\title{
THE RATE OF SUBSTITUTION BETWEEN ECONOMIC AND SOCIOEMOTIONAL WEALTH IN FAMILY FIRM IPO UNDERPRICING
}

\author{
ANDREA SIGNORI \\ Università Cattolica del Sacro Cuore \\ Largo Gemelli, 1, 20123 Milan, Italy \\ JOSIP KOTLAR \\ ALFREDO DE MASSIS \\ Lancaster University Management School, UK \\ SILVIO VISMARA \\ University of Bergamo, Italy
}

\begin{abstract}
This study investigates differences in IPO underpricing between family and nonfamily firms. Using a sample of 1,743 IPOs occurring in seven European countries from 1995 to 2011, we show that the relationship between family firm status and IPO underpricing is contingent on the degree of share retention.
\end{abstract}

\section{INTRODUCTION}

A rich literature investigating the influence of family ownership suggests that family firms' strategic choices involve trade-offs between economic and socioemotional wealth (Allen \& Panian, 1982; Chrisman, Chua, \& Sharma, 2005; Gómez-Mejía et al., 2007; Gómez-Mejía et al., 2013). The inherent dilemma between economic and socioemotional wealth in family firms becomes particularly visible and quantifiable when considering IPO pricing decisions. The IPO is an important means for raising growth capital and diversifying family wealth, but such economic benefits come at the expenses of family control and influence, that must be relinquished to nonfamily shareholders.

Drawing from the behavioral agency model, Leitterstorf and Rau (2014) (LR) recently show that family firms accept higher IPO underpricing than nonfamily firms and suggest that the underpricing gap between family and nonfamily firms proxies the rate of substitution at which family firms trade economic wealth for socioemotional wealth in their strategic decisions. Despite its important theoretical implications, the evidence presented by LR raises several concerns that motivate us to replicate their study and extend that work in three important respects. First, we address doubts as to whether LR's findings are idiosyncratic to their sample or whether their theory can be generalized to a broader population of family firms. Second, we address the potentially biased estimates of the effect of family ownership due to important omitted variables. Third, we address the contradictions between Leitterstorf and Rau's (2014) assumption that IPO pricing decisions invariably and uniformly increase or reduce 
socioemotional wealth and the conclusions of other studies showing that heterogeneity of family owners' goals leads to variations in family firm behavior (Chrisman \& Patel, 2012).

In view of these outstanding limitations, the purpose of this paper is to reexamine the socioemotional wealth explanation for differences in IPO underpricing between family and nonfamily firms and extend Leitterstorf and Rau's (2014) basic findings by developing and testing an hypothesis that seeks to explain why there is variation in the relationship between family ownership and IPO underpricing.

\section{OVERVIEW OF THIS RESEARCH}

Firm owners obtain the greatest economic return from IPO when they sell their equity at a high price. From the perspective of firm owners who sell their equity to the stock market, IPO underpricing represents 'money left on the table', that is the market-ascribed value firm owners do not receive when their equity is sold to the first-day IPO subscribers (Ritter, 1987; Ritter \& Welch, 2002). Therefore, firm owners wishing to maximize the economic returns from IPO will try to minimize underpricing. LR identify three critical noneconomic benefits for which family owners are willing to sacrifice their economic wealth by accepting higher IPO underpricing. Those three explanations are referred to as the 'ownership dispersion hypothesis', the 'litigation risk hypothesis' and the 'informational cascade hypothesis'.

\section{Theoretical Extension: Introducing Heterogeneity of Family Owners' Goals}

Overall, Leitterstorf and Rau's (2014) work implies that family firms are more likely to accept higher IPO underpricing than nonfamily firms. However, their conclusion that family firms "appear rather homogeneous with respect to IPO underpricing" (p. 757) contradicts a substantial body of research indicating that family firms with similar configurations in family involvement behave with large unexplained heterogeneity (Chrisman \& Patel, 2012; Chrisman, Fang, Kotlar \& De Massis, 2015). Our argument is that the individual values, desires, and motives of family owners are arguably numerous and often competing, such that the same level of family ownership can be associated with completely opposite strategic choices (e.g., Kotlar \& De Massis, 2013). In the specific case of IPO pricing decisions, prior research has shown that owners 'go public' for different reasons (see Pagano, Panetta, \& Zingales, 1998). On the one hand, the IPO can be used to raise financial resources needed to sustain firm growth or rebalance the firm's capital structure. On the other hand, the IPO can be part of an exit strategy that allows existing shareholders to cash out at the listing, or closely thereafter (Mikkelson, Partch, \& Shah, 1997). Consistent with prior IPO literature (Leland \& Pyle, 1977; Zingales, 1995), if growth is the primary goal of firm owners, we should expect pre-IPO owners to sell a smaller portion of their shares at the IPO. On the contrary, if firm owners see the IPO as an exit and wealth diversification strategy, we should expect the portion of equity sold at the IPO to be greater. In turn, we expect that family control is a necessary condition without which the family cannot 
possess socioemotional wealth (Zellweger et al., 2012). Hence, we argue that family owners will consider socioemotional wealth in their IPO pricing decisions only if they intend to keep their ownership and control position in the firm. In view of these considerations, the external validity of the Leitterstorf and Rau's (2014) theory might be limited to markets, such as the German Stock Exchange between 2004 and 2011, characterized by low valuation ratios which discourage exits through IPOs and ingenerate incentives for high equity retention in those firms that still go public. To address this issue we extend the boundary conditions for the effect of family ownership on IPO underpricing by proposing the following hypothesis:

\section{Hypothesis 1: The positive impact of family ownership on IPO underpricing is contingent on the degree of share retention, such that family firms will accept higher IPO underpricing only when their primary goal is sustaining firm growth rather than selling the firm.}

\section{METHODS}

\section{Sample}

The sample is made of 1,743 IPOs occurring in seven European countries (namely, Belgium, France, Germany, Italy, Netherlands, Portugal, and UK) from 1995 to 2011. Our main source of information was the EurIPO database, containing data and offering prospectuses of the population of IPOs that took place in all major European stock exchanges since 1995. Data were codified from each firm's official IPO prospectus, filed with the stock exchange regulatory authority. Financial and ownership information that were missing or partially reported in IPO prospectuses were manually collected from other databases, namely Datastream and Amadeus.

\section{Analysis and Measures}

The study involves both a replication and an extension of LR. First, we replicate Leitterstorf and Rau's (2014) model by adopting the same empirical setting, model specification and variable definition in a cross-sectional regression on the subsample of 153 IPOs occurred in Germany during the period 2004-2011. Second, we extend Leitterstorf and Rau's (2014) study in two directions: (1) we extend the sample both geographically and temporally, by running the same cross-sectional regression on our sample of 1,743 IPOs occurring in seven European countries from 1995 to 2011; (2) we improve the model specification, by addressing potential endogeneity concerns arising from omitted variables. In the third and final step, we extend Leitterstorf and Rau's (2014) work by testing our new proposed hypothesis on the heterogeneity of IPO underpricing among family firms and the role of family owners' goals.

In all our analyses, the dependent variable is IPO underpricing, defined as the first day closing price minus the offer price, divided by the offer price (Beatty \& Ritter, 1986). The explanatory variable is the dummy variable family firm status indicating that voting rights are concentrated in the hands of an individual and/or his family. We reconstructed the ownership and control chain of all firms to identify whether an individual or a family owns, directly and 
indirectly, more than $20 \%$ of the firm's decision-making rights (Faccio \& Lang, 2002). Control variables are selected based on prior IPO research (e.g., Butler, O'Connor Keefe, \& Kieschnick, 2014) and include (1) underwriter reputation, defined as the market share of the lead underwriter measured as the sum of IPO values underwritten by the same underwriter in our sample, (2) firm size, defined as the natural logarithm of pre-IPO annual sales, (3) firm age, defined as the natural logarithm of one plus the difference between IPO year and the firm's founding year, and (4) venture capital $(V C)$ backing, a dummy variable indicating whether the IPO is conducted by a VC-backed firm.

To improve the model specification of LR's analysis, we particularly focus on outstanding omitted variables listed in Butler et al. (2014), namely (1) market momentum variable, defined as the average daily return of the corresponding market index over 30 days prior to the IPO date, as in Lowry \& Murphy (2007), (2) average industry enterprise value to sales ratio (EV/Sales) computed similar to Bhojraj \& Lee (2002), and (3) prior 30 days underpricing, defined as the average underpricing of IPOs occurring in the same stock exchange over the 30 days prior to the IPO date, as in Bradley \& Jordan (2002).

In order to test our hypothesis that IPO underpricing of family firms varies depending on family owners' goals associated with the IPO, in the final stage of our study we explicitly account for such goals. As noted earlier, the extent to which controlling shareholders retain equity is perhaps the most meaningful indicator of whether they pursue the IPO as a means for selling the firm or raising capital for growth (Habib \& Ljungqvist, 2001). Therefore, we proxy differences in family owners' goals by measuring the overhang, which is the number of pre-IPO shares retained divided by the total number of shares offered.

\section{RESULTS}

As documented by tests on the difference in means and medians, the level of underpricing associated with family IPOs $(21.3 \%$ on average $)$ is not statistically different from that of nonfamily IPOs (24.1\%).

\section{Replication and Extension of Leitterstorf and Rau (2014)}

Replication. Our analysis corroborates the evidence obtained by LR according to which family firms are associated with higher underpricing when going public. The only discrepancy lies in the magnitude of the coefficient: while LR find that family firms experience, on average, a $10 \%$ higher underpricing, in our study this number decreases to $4 \%$. Overall, we can argue that our replication confirms the results obtained by LR.

Sample extension. When the sample of IPOs is extended to the period 1995-2011 and to other European countries, the coefficient of the family firm variable is not significant. Therefore, our reexamination of LR's work suggests that the relationship between family firm status and IPO underpricing found by LR cannot be generalized to other European countries and periods of time. 
Omitted variables bias. Consistent with prior literature, we find that the omitted variables significantly contribute to explain the cross-sectional variation in IPO underpricing and correlate with the explanatory variable, that is family firm status. Therefore, these factors not only influence the level of IPO underpricing, but also a family's propensity to conduct an IPO. In other words, more favorable market conditions, higher industry valuations, and higher prior IPO underpricing are associated with a lower likelihood of observing a family firm going public. This testifies that the exclusion of these important determinants of IPO underpricing causes biased estimates of the effect of the family firm status on IPO underpricing.

\section{Heterogeneity of Family Firms: The Role of Family Owners' Goals}

The coefficient of the interaction term between family firm variable and overhang is positive and significant at the $1 \%$ level, the result being robust to the inclusion of the three omitted variables in the model. These findings support our hypothesis that the relationship between family firm status and IPO underpricing is positively moderated by the degree of share retention. When the family owners' goal in taking the company public is that of raising capital while simultaneously retaining control in the firm, as indicated by a higher level of overhang, they trade their economic wealth for socioemotional wealth. Therefore, the results suggest that the rate of substitution between economic and socioemotional wealth is not homogeneous among family firms. More specifically, our estimates indicate that the rate of substitution is negligible when family owners do not retain a significant amount of ownership in the firm; for each additional unit of overhang family owners are willing to sell their shares at a $2 \%$ discount, relative to the first day market price.

\section{DISCUSSION AND CONCLUSION}

Perhaps the most surprising result of this study was that the relationship between family ownership and IPO underpricing was not significant after the methodological refinements introduced in our study, namely the extension of the sample in both geographical and temporal terms and the inclusion of exogenous control variables. As such, LR's evidence appears peculiar to a specific empirical setting (i.e., IPOs listed in Germany in the period 2004-2011), and not robust to different model specifications. Hence, LR's conclusions cannot be directly generalized to broader populations of IPOs. Given that the present study employed relatively more precise methods than in LR while preserving the basic model and logic of the original study, one conclusion might be that socioemotional wealth offers a somewhat less complete explanation for differences in IPO underpricing between family and nonfamily firms than previously thought. However, we proposed an alternative explanation that takes a more thorough consideration of the distinctive characteristic of IPO activity in Germany between 2004 and 2011 and reevaluates the socioemotional wealth argument.

Our replication and extension of LR has yielded two outstanding conclusions that advance understanding of strategic behavior of family firms. First, our study supported the 
notion that socioemotional wealth is a primary driver of strategic behavior in family firms (Gómez-Mejía et al., 2007) as well as LR's intuition that IPO underpricing reflects the rate of substitution between economic and socioemotional wealth. However, our study advanced those views by showing that family owners' goals for continued family control play a key role for IPO underpricing. Second, our study supports LR's idea that socioemotional wealth can be quantified at the IPO and that family owners are willing to trade their economic wealth (i.e., accept higher underpricing) for socioemotional wealth (i.e., control retention) by accepting higher IPO underpricing. Yet, our theoretical and empirical refinements yielded a more precise measure of the rate of substitution between socioemotional wealth and economic wealth by incorporating information about overhang. Contrary to LR, our findings suggest that the rate of substitution is not homogeneous among family firms.

Our analysis is not exempt from limitations that future research should take into account. First, our conclusions do not consider how the relative importance of family goals varies across the life-cycle of the firm (e.g., Gersick et al., 1997). Therefore, our conclusions should be generalized with caution to other countries and markets. Second, our study has emphasized the role of family owners' goals for continued family control but scholars have recently noted that socioemotional wealth encompasses many different family priorities (Berrone, Cruz, \& GómezMejía, 2012) and that such priorities may be salient to different strategic decisions (e.g., Miller \& Le Breton-Miller, 2014). Exploring these issues emerges as a fruitful direction for future work.

Our study also points to important implications for IPO practice. LR's study suggested that IPO investors could simply favor investments in family firm IPOs rather than nonfamily firm IPOs in order to benefit from higher IPO underpricing. Our results indicate that such investment strategy may not be always effective, especially in stock markets characterized by high growth opportunities and superior long-term returns such as financial bubbles. Yet, IPO investors can combine insights about the stock market with evidence about ownership retention

to make more informed decisions and discriminate family firm IPOs that are driven primarily by growth rather than exit goals.

In conclusion, by replicating and extending LR's attempt to quantify socioemotional wealth, this study helps advance theoretical understanding of strategic behavior in family firms by pointing to the crucial role of family owners' goals and refining the measure of the rate at which family owners trade economic wealth for socioemotional wealth in their strategic decisions.

\section{REFERENCES AVAILABLE FROM THE AUTHORS}

